\title{
Prevalence and sociodemographic determinants of household- level double burden of malnutrition in Bangladesh
}

\author{
Subhasish Das ${ }^{1, *}$, Shah Mohammad Fahim ${ }^{1}$, Md Saimul Islam², Tuhin Biswas ${ }^{3}$, \\ Mustafa Mahfuz ${ }^{1,4}$ and Tahmeed Ahmed' \\ ${ }^{1}$ Nutrition and Clinical Services Division, International Centre for Diarrhoeal Disease Research, Bangladesh (icddr,b), \\ 68 Shaheed Tajudddin Ahmed Sarani, Mohakhali, Dhaka 1212, Bangladesh: ${ }^{2}$ Department of Statistics, University \\ of Rajshahi, Rajshahi, Bangladesh: ${ }^{3}$ Institute for Social Science Research, University of Queensland, Brisbane, \\ Australia: ${ }^{4}$ Faculty of Medicine and Life Sciences, University of Tampere, Tampere, Finland
}

Submitted 5 May 2018: Final revision received 31 August 2018: Accepted 9 November 2018: First published online 7 January 2019

\begin{abstract}
Objective: To investigate the prevalence and sociodemographic determinants of household-level mother-child double burden (MCDB) of malnutrition in Bangladesh. Design: The analysis was done using Bangladesh Demographic and Health Survey 2014 data. Multivariable logistic regression identified the sociodemographic factors associated with double-burden households.

Setting: Nationally representative cross-sectional survey.

Participants: A total of 5951 households were included in the analysis.

Results: A coexistence of overweight or obese mother and underweight or stunted or wasted child (OWOBM/USWC) was found in $6 \cdot 3 \%$ households. The prevalence of overweight or obese mother and underweight child (OWOBM/UWC) was $3.8 \%$, of overweight or obese mother and stunted child (OWOBM/STC) was $4.7 \%$, and of overweight or obese mother and wasted child (OWOBM/WSC) was $1.7 \%$. Mother's age 21-25 years at first birth, middle wealth index group, having two or three children and having four or more children showed statistically significant $(P<0.05)$ associations with OWOBM/UWC. Households with mother's age 21-25 years at first birth, middle wealth index group, no exposure to information media, having two or three children and having four or more children had higher odds of OWOBM/STC and OWOBM/USWC which were statistically significant $(P<0.05)$. Delivery of child through caesarean section was significantly associated with OWOBM/USWC $(P<0 \cdot 05)$.

Conclusions: Although the prevalence of MCDB of malnutrition in Bangladesh is low, prevention programmes must consider the nutrition concerns of the entire household to prevent future risks. Such programmes also need to be tagged with family planning and increasing awareness through social and behaviour change counselling and exposure to information media.
\end{abstract}

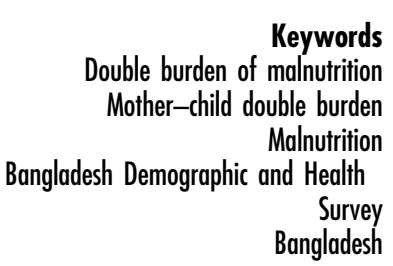

Double burden of malnutrition (DBM) refers to the coexistence of undernutrition and overnutrition in the same setting ${ }^{(1,2)}$. This phenomenon can occur at individual level, household level and even at population level ${ }^{(1)}$. DBM becomes evident when the slower reduction rate of undernutrition is coupled with a faster increasing rate of overnutrition $^{(3)}$. Evidence suggests that along with demographic and socio-economic transitions, developing countries are experiencing a nutritional transition ${ }^{(4)}$. Rapid urbanization, economic development, consumption of less plant-based, more refined and energy-dense foods, and decreased physical activity are the factors reported to be responsible for this ${ }^{(5)}$. Over- and undernutrition - both axes of malnutrition - are equally harmful. Undernutrition hinders physical and intellectual development ${ }^{(6)}$, whereas overnutrition acts as a significant contributor to various non-communicable diseases ${ }^{(7)}$. At household level the most common duo is the coexistence of undernourished children and overweight or obese mothers, which is commonly known as mother-child dual burden (MCDB) of malnutrition ${ }^{(8,9)}$

Studies done in different parts of the world have reported the presence of MCDB of malnutrition at household level. In Brazil the prevalence of MCDB was $11.0 \%$ and in China it was $8.0 \%{ }^{(8)}$. A study done in rural west Java reported the prevalence of household-level 
MCDB as $30.6 \%$, whereas in the Gaza Strip of Palestine it was $15.7 \%{ }^{(5)}$. According to the Bangladesh Nutritional Surveillance Project (2003-2006), the prevalence of MCDB of malnutrition in rural Bangladesh was $4 \%{ }^{(10-12)}$. Reports from national surveys indicate that the trend of being overweight or obese among Bangladeshi women of reproductive age is on a steady rise, whereas the prevalence of childhood undernutrition is not declining at a desired rate ${ }^{(10)}$. Among Bangladeshi children under 5 years of age, $36 \%$ are stunted, $14 \%$ are wasted and $33 \%$ are underweight, whereas the prevalence of overweight/ obesity among ever-married Bangladeshi women is $24 \%{ }^{(10)}$. But to our knowledge, no analysis has been done using countrywide data to explore the existing scenario of household-level DBM among mother-child pairs living in Bangladesh.

Household-level DBM is an important concern from a public health perspective. The burden has been accelerated in low- and middle-income countries (LMIC) over the past few decades and confers serious impact on health, productivity and economic growth ${ }^{(13)}$. It has already been reported that the malnutrition double burden is linked with persistence of adverse conditions such as high level of food insecurity, intake of energy-dense foods, higher prevalence of infection, and inadequate access to water and health-care services ${ }^{(3)}$. These factors, in association with rapid population growth and urbanization, may lead to an increase in the prevalence of DBM and subsequent adverse effects in the country. Hence, identifying the determinants of MCDB of malnutrition can help nutritionists as well as policy makers to direct effective and specific interventions for preventing and controlling malnutrition in all its forms. Understanding the DBM and its determinants is essential to meet the healthrelated Sustainable Development Goals ${ }^{(13)}$. Considering the above-mentioned context, we aimed to measure the prevalence and to identify sociodemographic determinants of household-level MCDB of malnutrition in Bangladesh.

\section{Methods}

\section{Study design}

The present study is based on analysis of Bangladesh Demographic and Health Survey (BDHS) 2014 data. The 2014 BDHS was a nationally representative cross-sectional survey conducted between 28 June and 9 November of 2014 by the National Institute of Population Research and Training, ICF International (USA), and Mitra and Associates. Participants in the BDHS were selected using probability-proportional-to-size sampling based on a twostage cluster sample of households and stratified by rural and urban areas in the seven administrative regions of Bangladesh. The detailed protocol and methods have been published elsewhere ${ }^{(10)}$. The survey selected 18000 residential households, where 17565 were found occupied. Interviews were successfully completed in 17300 (99\%) households with a response rate of $98 \%$ from evermarried women aged 15-49 years. Informed consent was obtained from the participants after notifying them about the purpose of the survey.

\section{Anthropometric measurements and nutritional status}

In order to assess nutritional status, height and weight of the participants were measured by trained field research staff using standardized procedures. For mothers, BMI was calculated as [weight $(\mathrm{kg})] /[\text { height }(\mathrm{m})]^{2}$. The BMI cut-off used for overweight was 25.0 to $<30.0 \mathrm{~kg} / \mathrm{m}^{2}$, and for obesity it was $\geq 30.0 \mathrm{~kg} / \mathrm{m}^{2(14)}$. Children were referred as undernourished when they were stunted, wasted or underweight. Stunting was defined as length-for-age or height-for-age less than 2 sD below the median length-forage or height-for-age of the WHO reference population (i.e. length-for-age $Z$-score (LAZ) or height-for-age $Z$-score $($ HAZ $<-2)$. Wasting was defined as having a weight-forlength $Z$-score (WLZ) or weight-for-height $Z$-score (WHZ) of $<-2$, and underweight as having a weight-for-age $Z$-score (WAZ) of $<-2$, compared with the respective median of the WHO reference population.

\section{Outcome variables}

The extent of our current analysis was limited to household-level DBM where the mother was overweight or obese (OWOBM) and at least one of her children under 5 years of age was undernourished. We had four different forms of DBM in the analysis as outcome variables. In all the forms, the mother was either overweight or obese. If the child was underweight, then the DBM was termed as OWOBM/UWC; OWOBM/STC indicates that the child was stunted, OWOBM/WSC indicates that the child was wasted; and OWOBM/USWC indicates the overweight or obese mother was paired with her child having at least one form of undernutrition (underweight or stunted or wasted).

\section{Sociodemographic factors}

Sociodemographic characteristics of the participants were collected using a validated questionnaire which was administered during a face-to-face interview. Education variables were categorized as no education (indicating 0 grade), primary education (indicating completed grade $1-5)$, secondary education (indicting completed grade 6-10) and higher education (indicating completed more than grade 10). Households were categorized based on living in urban or rural areas. A composite score named the 'household wealth index', which was calculated using principal components analysis and already included in DHS data set, was used for the current analysis. The index 
was calculated based on the household's ownership of selected assets, availability of electricity supply, television and bicycle; materials used for housing construction; types of water access and sanitation facilities; use of health and other services; and health outcomes. Information on child's size at birth was collected according to the recall statement of the mother.

\section{Statistical analysis}

A total of 5951 households where a mother had at least one child under 5 years of age were included in the analysis. If a family had two or more children within the age range (0-59 months), the oldest one was selected for the mother-child pair. Prevalence was calculated by dividing the number of DBM households by the total number of households and multiplying by 100 . We applied frequency distribution to summarize the categorical variables and descriptive statistics to summarize the continuous variables. Firth's logistic regression analysis was performed to identify the sociodemographic factors associated with the DBM. Firth's penalization stabilizes the bias in predicted probabilities when the outcome of interest is rare ${ }^{(15)}$. The variables found to be statistically significant $(P<0.05)$ in the bivariate analysis were considered for the multivariable analysis. Households having normal-weight mother $\left(\mathrm{BMI}=18.5-24.9 \mathrm{~kg} / \mathrm{m}^{2}\right)$ and nonmalnourished child pairs (1778 households, 29.9\%) were counted as the comparison group for regression analysis. We reported OR with $95 \% \mathrm{CI}$ and considered $P<0.05$ as the cut-off level of statistical significance. The complex sampling design with weighted sample was adjusted for in all statistical analyses. We performed likelihood ratio tests to evaluate the model goodness-of-fit (see online supplementary material, Supplemental Table 1) and the statistics suggested that all the models were a good fit (likelihood ratio test values for OWOBM/UWC, OWOBM/STC, OWOBM/WSC and OWOBM/USWC models are 74.79221 $(P=0.0014), 74.46098(P=0.00083), 25.76653(P=0.04)$ and $112.8807(P=0 \cdot 0014)$, respectively). Firth's logistic regression analyses were performed using the 'logistf' package in $R^{(16)}$.

\section{Results}

\section{Sociodemographic characteristics}

Table 1 describes the sociodemographic characteristics of the participants. The mean age of the mothers was 25.65 (SD 5.98) years. Only $14.8 \%$ of mothers did not receive any formal education and $11.1 \%$ had higher education. Only half of the mothers $(47 \cdot 1 \%)$ and onethird of the fathers $(31.3 \%)$ attained secondary education. Approximately $75 \%$ of the mothers did not have any employment and the remaining $25 \%$ were working to earn money. Almost two-thirds of the participants
Table 1 Sociodemographic characteristics of the respondents (n 5951). Data from the Bangladesh Demographic and Health Survey 2014

\begin{tabular}{|c|c|c|}
\hline Characteristic & Mean or $n$ & SD or $\%$ \\
\hline Mother's age (years), mean and SD & $25 \cdot 65$ & 5.98 \\
\hline Child's age (months), mean and SD & 30.9 & $16 \cdot 9$ \\
\hline Mother's age at first birth (years), mean and SD & $18 \cdot 27$ & 3.33 \\
\hline Total children ever born, mean and SD & $2 \cdot 3$ & 1.5 \\
\hline \multicolumn{3}{|l|}{ Mother's education, $n$ and $\%$} \\
\hline No education & 881 & 14.80 \\
\hline Primary & 1608 & 27.02 \\
\hline Secondary & 2801 & $47 \cdot 07$ \\
\hline Higher & 661 & $11 \cdot 11$ \\
\hline \multicolumn{3}{|l|}{ Mother currently working, $n$ and $\%$} \\
\hline Yes & 1513 & $25 \cdot 4$ \\
\hline No & 4437 & 74.6 \\
\hline \multicolumn{3}{|l|}{ Father's education, $n$ and $\%$} \\
\hline No education & 1412 & 23.7 \\
\hline Primary & 1779 & 29.9 \\
\hline Secondary & 1863 & $31 \cdot 3$ \\
\hline Higher & 896 & $15 \cdot 1$ \\
\hline \multicolumn{3}{|l|}{ Father's occupation, $n$ and $\%$} \\
\hline Farmer & 1404 & 23.6 \\
\hline Labour & 1194 & $20 \cdot 1$ \\
\hline Service/businessman & 3176 & 53.4 \\
\hline Others (unemployment, retired) & 138 & $2 \cdot 3$ \\
\hline \multicolumn{3}{|l|}{ Place of residence, $n$ and $\%$} \\
\hline Urban & 1926 & 32.4 \\
\hline Rural & 4025 & $67 \cdot 6$ \\
\hline \multicolumn{3}{|l|}{ Wealth index quintile, $n$ and $\%$} \\
\hline Poorest & 1232 & $20 \cdot 7$ \\
\hline Poor & 1101 & $18 \cdot 5$ \\
\hline Middle & 1178 & $19 \cdot 8$ \\
\hline Rich & 1239 & $20 \cdot 8$ \\
\hline Richest & 1201 & $20 \cdot 2$ \\
\hline \multicolumn{3}{|l|}{ Family exposed to media, $n$ and $\%$} \\
\hline Television/radio/newspaper & 2173 & $36 \cdot 5$ \\
\hline Not at all & 3778 & 63.5 \\
\hline \multicolumn{3}{|l|}{ Received deworming drug, $n$ and $\%$} \\
\hline Yes, last two week & 2281 & 38.4 \\
\hline No & 3662 & 61.6 \\
\hline \multicolumn{3}{|l|}{ Reported fever ( $n$ 2948), $n$ and \% } \\
\hline Yes, last two week & 1024 & 34.7 \\
\hline No & 1924 & $65 \cdot 3$ \\
\hline \multicolumn{3}{|l|}{ Ever vaccinated, $n$ and $\%$} \\
\hline Yes & 1872 & 31.5 \\
\hline No & 4071 & 68.5 \\
\hline \multicolumn{3}{|l|}{ Place of delivery ( $n$ 3977), $n$ and $\%$} \\
\hline At home & 2373 & $59 \cdot 7$ \\
\hline Government hospital & 551 & 13.9 \\
\hline Private hospital/clinic & 931 & 23.4 \\
\hline Others (NGO) & 122 & 3.1 \\
\hline \multicolumn{3}{|l|}{ Had C-section delivery ( $n$ 3976), $n$ and \% } \\
\hline Yes & 950 & $24 \cdot 0$ \\
\hline No & 3026 & $76 \cdot 0$ \\
\hline \multicolumn{3}{|l|}{ Size of child at birth, $n$ and $\%$} \\
\hline Larger than average & 538 & 13.5 \\
\hline Average & 2693 & $67 \cdot 7$ \\
\hline Smaller than average & 748 & $18 \cdot 8$ \\
\hline
\end{tabular}

NGO, non-governmental organization; C-section, caesarean section.

lived in rural areas. Two-thirds (63.5\%) of the families had never been exposed to any type of information media. The mean age of the mothers at first pregnancy was 18.27 (SD 3.33 ) years. Of the mothers, $60 \%$ delivered their child at home and $76 \%$ of the deliveries were normal deliveries. A total of $18.8 \%$ of the children were born smaller than average. 


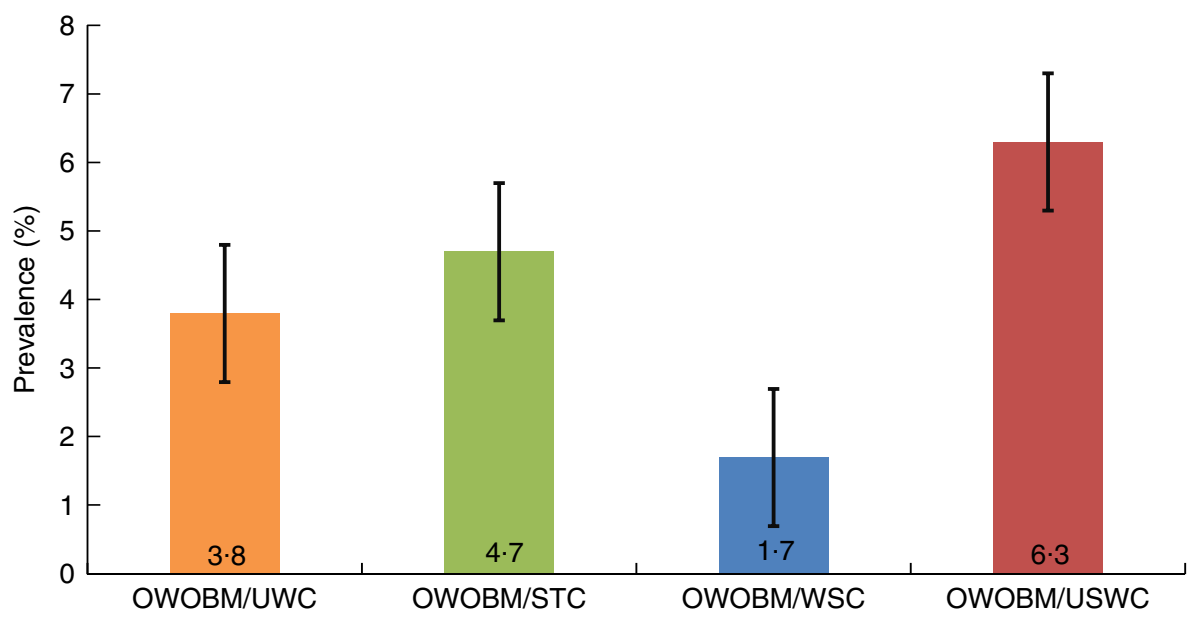

Fig. 1 (colour online) Prevalence of household-level mother-child double burden of malnutrition in Bangladesh ( $n 5951)$, with $95 \%$ $\mathrm{Cl}$ represented by vertical bars. Data from the Bangladesh Demographic and Health Survey 2014 (OWOBM/UWC, overweight or obese mother and underweight child; OWOBM/STC, overweight or obese mother and stunted child; OWOBM/WSC, overweight or obese mother and wasted child; OWOBM/USWC, overweight or obese mother and underweight or stunted or wasted child)

\section{Prevalence of double burden of malnutrition}

Figure 1 represents the prevalence of different forms of DBM among mother-child pairs. The prevalence of overweight or obese mother and underweight child was 3.8 (95\% CI $3.3,4.3) \%$, of overweight or obese mother and stunted child was 4.7 (95\% CI 4.2, 5.3) \% and of overweight or obese mother and wasted child was 1.7 (95\% CI 1.4, $2 \cdot 1) \%$. The coexistence of overweight or obese mother and undernourished child (underweight or stunted or wasted) was observed in 6.3 (95\% CI 5.8, 7.1)\% of households.

\section{Factors associated with housebold-level double burden of malnutrition}

Table 2 presents the factors associated with DBM among mother-child pairs at household level in the bivariate analysis, and Table 3 presents the results of the multivariable analysis. The presence of OWOBM/UWC showed statistically significant positive associations (all $P<0.05$ ) with mother's age being 21-25 years at first birth $(\mathrm{OR}=2 \cdot 40 ; 95 \% \mathrm{CI} 1 \cdot 32,4.52)$, middle wealth index group $(\mathrm{OR}=3.23 ; 95 \%$ CI $1.56,7 \cdot 22)$, family never exposed to information media (OR $=1.90 ; 95 \%$ CI $1 \cdot 13,3 \cdot 27)$, having two or three children $(\mathrm{OR}=2 \cdot 71 ; 95 \% \mathrm{CI} 1 \cdot 07,4 \cdot 47)$ and having four or more children (OR $=4.03$; $95 \%$ CI $2 \cdot 14$, 7.54). Size of the child larger than average at birth was found to be protective against OWOBM/UWC (OR =0.41; 95\% CI 0.18, 0.83; $P<0 \cdot 05)$.

A similar result was found for OWOBM/STC households. The statistically significant determinants (all $P<0.05$ ) of OWOBM/STC included mother's age at first birth being $16-20$ years $(\mathrm{OR}=1 \cdot 83 ; 95 \% \mathrm{CI} 1 \cdot 10,3 \cdot 24)$ and $21-25$ years $(\mathrm{OR}=2.45 ; 95 \%$ CI $1.32,4.70)$, middle wealth index group (OR $=1.96 ; 95 \%$ CI $1.07,3.70)$, having two or three children (OR $=2.49 ; 95 \% \mathrm{CI} 1.66,3 \cdot 80)$ and having four or more children (OR $=4 \cdot 09 ; 95 \%$ CI $2 \cdot 35,7 \cdot 06)$. No history of being vaccinated was found to be protective against OWOBM/STC $(\mathrm{OR}=0.67 ; 95 \%$ CI $0.47,0.97 ; P<0.05)$.

For OWOBM/USWC, households with mother's age being 21-25 years at first birth $(\mathrm{OR}=1.97$; $95 \%$ CI $1 \cdot 18$, $3.32 ; \quad P<0.05)$, no exposure to information media $(\mathrm{OR}=1.47 ; 95 \%$ CI $1.01,2 \cdot 22 ; P<0.05)$, delivery of child through caesarean section (C-section; OR $=1.68 ; 95 \% \mathrm{CI}$ $1.20,2.33 ; \quad P<0.05)$, having two or three children $(\mathrm{OR}=2.59 ; 95 \% \mathrm{CI} 1.84,3.71 ; P<0.05)$ and having four or more children $(\mathrm{OR}=4.72 ; 95 \%$ CI $2.93,7.60, P<0.05)$ were associated with significantly higher odds of MCBD of malnutrition. No such statistically significant associations were found between selected sociodemographic determinants and OWOBM/WSC households.

\section{Discussion}

Our study found a low prevalence of household-level MCDB of malnutrition in Bangladesh. This finding is in line with the results from other studies conducted in LMIC. The proportion of OWOBM/STC was less than $10 \%$ in most of the countries, except in some African and Latin American countries such as Egypt (12.5\%), Ghana (12.5\%), Nicaragua (12.5\%), Bolivia (15\%), Peru (16\%) and Guatemala $(23 \%)^{(17)}$. Previous studies conducted in rural Indonesia and Bangladesh estimated the prevalence of OWOBM/ STC at household level to be 11 and $4 \%$, respectively ${ }^{(12)}$. Our result regarding household-level OWOBM/UWC burden is in accordance with the reports from eighteen LMIC of South Asia, Africa and Latin America, where the prevalence of OWOBM/UWC ranged from 0.3 to $5 \cdot 3 \%^{(18,19)}$. We found that the prevalence of OWOBM/ WSC is only $1.7 \%$ in Bangladesh. The prevalence of wasting (14\%) is much lower in the country compared with stunting $(36 \%)$ and underweight $(33 \%)^{(10)}$. This 
Table 2 Bivariate analysis of unadjusted OR with $95 \% \mathrm{Cl}$ for different forms of household-level mother-child double burden of malnutrition in Bangladesh, by maternal and child characteristics ( $n$ 5951). Data from the Bangladesh Demographic and Health Survey 2014

\begin{tabular}{|c|c|c|c|c|c|c|c|c|c|}
\hline \multirow[b]{2}{*}{ Characteristic } & \multirow[b]{2}{*}{ Response } & \multicolumn{2}{|c|}{ OWOBM/UWC } & \multicolumn{2}{|c|}{ OWOBM/STC } & \multicolumn{2}{|c|}{ OWOBM/WSC } & \multicolumn{2}{|c|}{ OWOBM/USWC } \\
\hline & & OR & $95 \% \mathrm{Cl}$ & OR & $95 \% \mathrm{Cl}$ & OR & $95 \% \mathrm{Cl}$ & OR & $95 \% \mathrm{Cl}$ \\
\hline \multirow[t]{4}{*}{ Mother's education } & No education & & Ref. & & Ref. & & Ref. & & Ref. \\
\hline & Primary & 0.81 & $0.54,1.24$ & 0.99 & $0.68,1.46$ & 1.08 & $0 \cdot 55,2 \cdot 21$ & 1.01 & $0.72,1.43$ \\
\hline & Secondary & 0.82 & $0.56,1.2$ & 0.96 & $0.68,1.38$ & $1 \cdot 10$ & $0.60,2.16$ & 1.06 & $0.77,1.46$ \\
\hline & Higher & 1.06 & $0.65,1.72$ & 1.09 & $0.68,1.72$ & $2 \cdot 33^{*}$ & $1 \cdot 17,4.86$ & 1.42 & $0.96,2 \cdot 10$ \\
\hline \multirow[t]{4}{*}{ Mother's age at first birth } & $\leq 15$ years & & Ref. & & Ref. & & Ref. & & Ref. \\
\hline & $16-20$ years & $1 \cdot 27$ & $0.88,1.91$ & $1 \cdot 74^{\star}$ & $1 \cdot 21,2 \cdot 56$ & 1.47 & $0 \cdot 83,2 \cdot 84$ & $1 \cdot 71^{*}$ & $1 \cdot 24,2 \cdot 39$ \\
\hline & $21-25$ years & $1.77^{*}$ & $1 \cdot 12,2 \cdot 83$ & $1.88^{*}$ & $1 \cdot 21,2.96$ & $2 \cdot 16^{*}$ & $1.08,4.48$ & $2 \cdot 11^{*}$ & $1 \cdot 44,3 \cdot 12$ \\
\hline & $\geq 26$ years & 1.28 & $0.56,2.65$ & 0.79 & $0.28,1.83$ & $2 \cdot 17$ & $0.72,5.73$ & 1.04 & $0.48,2.04$ \\
\hline \multirow[t]{2}{*}{ Mother currently working } & Yes & & Ref. & & Ref. & & Ref. & & Ref. \\
\hline & No & $1 \cdot 19$ & $0.87,1.66$ & $1 \cdot 16$ & $0.88,1.55$ & 1.35 & $0 \cdot 84,2 \cdot 25$ & $1 \cdot 16$ & $0.91,1.49$ \\
\hline \multirow[t]{4}{*}{ Father's education } & No education & & Ref. & & Ref. & & Ref. & & Ref. \\
\hline & Primary & 1.05 & $0.72,1.53$ & $1 \cdot 11$ & $0.8,1.57$ & 0.97 & $0.52,1.86$ & $1 \cdot 18$ & $0.87,1.60$ \\
\hline & Secondary & 0.98 & $0.68,1.43$ & 1.09 & $0.78,1.53$ & 1.64 & $0.94,2.97$ & 1.32 & $0.99,1.79$ \\
\hline & Higher & 1.41 & $0.93,2.13$ & 1.36 & $0.93,1.99$ & $2 \cdot 33^{*}$ & $1 \cdot 27,4.38$ & $1.70^{*}$ & $1 \cdot 22,2 \cdot 37$ \\
\hline \multirow[t]{4}{*}{ Father's occupation } & Farmer & & Ref. & & Ref. & & Ref. & & Ref. \\
\hline & Labour & 1.27 & $0.83,1.93$ & 1.27 & $0.88,1.86$ & 0.85 & $0.43,1.62$ & $1 \cdot 19$ & $0.84,1.67$ \\
\hline & Service/businessman & 1.33 & $0.95,1.91$ & 1.31 & $0.97,1.8$ & $1 \cdot 27$ & $0 \cdot 79,2 \cdot 13$ & $1.51^{*}$ & $1 \cdot 15,2 \cdot 00$ \\
\hline & Others (unemployment, retired) & 1.29 & $0.46,2.94$ & 0.63 & $0.17,1.63$ & 1.66 & $0.44,4.63$ & 0.94 & $0.37,2.00$ \\
\hline \multirow[t]{2}{*}{ Place of residence } & Urban & $1 \cdot 65^{\star}$ & $1 \cdot 26,2 \cdot 15$ & $1 \cdot 78^{\star}$ & $1 \cdot 39,2 \cdot 26$ & 1.35 & $0.89,2.01$ & $1.71^{*}$ & $1 \cdot 38,2 \cdot 10$ \\
\hline & Rural & & Ref. & & Ref. & & Ref. & & Ref. \\
\hline \multirow[t]{5}{*}{ Wealth index quintile } & Poorest & & Ref. & & Ref. & & Ref. & & Ref. \\
\hline & Poor & 1.37 & $0.83,2.27$ & 1.23 & $0.76,1.98$ & $1 \cdot 61$ & $0.76,3.53$ & 1.50 & $0.99,2.29$ \\
\hline & Middle & $2 \cdot 05^{\star}$ & $1 \cdot 30,3 \cdot 29$ & $2 \cdot 14^{\star}$ & $1.41,3.30$ & 1.60 & $0.77,3.48$ & $2 \cdot 22^{*}$ & $1.52,3.28$ \\
\hline & Rich & $1 \cdot 61^{*}$ & $1.01,2.62$ & $2 \cdot 09^{*}$ & $1 \cdot 39,3 \cdot 22$ & 1.61 & 3.47 & $2 \cdot 24^{*}$ & , 3.30 \\
\hline & Riches & $2 \cdot 40^{*}$ & $1.55,3 \cdot 80$ & $2 \cdot 50^{\star}$ & $1.67,3.83$ & $3.51^{*}$ & $1 \cdot 87,7 \cdot 14$ & $3 \cdot 13^{*}$ & $2 \cdot 19,4.57$ \\
\hline \multirow[t]{2}{*}{ Family exposed to media } & Television/radio/newspaper & & Ref. & & Ref. & & Ref. & & Ref. \\
\hline & Not at all & $1.49^{*}$ & $1 \cdot 12,2 \cdot 02$ & $1.52^{*}$ & $1 \cdot 17$ & $2 \cdot 03^{\star}$ & $1 \cdot 29,3 \cdot 32$ & $1.66^{*}$ & $1 \cdot 32,2 \cdot 11$ \\
\hline \multirow[t]{2}{*}{ Child's age } & $0-23$ months & & Ref. & & Ref. & & Ref. & & Ref. \\
\hline & $24-59 r$ & 2.42 & $1.76,3.38$ & 1.89 & $1.45,2.50$ & $1 \cdot 11$ & $0.74,1.68$ & $1 \cdot 66^{*}$ & $1 \cdot 33,2 \cdot 10$ \\
\hline Received deworming drug & $\begin{array}{l}\text { Yes, last } 2 \text { weeks } \\
\text { No }\end{array}$ & $1.59^{*}$ & $\begin{array}{l}1 \cdot 22,2 \cdot 08 \\
\text { Ref. }\end{array}$ & $1 \cdot 36^{\star}$ & $\begin{array}{l}1.07,1 \cdot 73 \\
\text { Ref. }\end{array}$ & 1.03 & $\begin{array}{l}0.68,1.54 \\
\text { Ref. }\end{array}$ & $1 \cdot 28^{*}$ & $\begin{array}{l}1.04,1.58 \\
\text { Ref. }\end{array}$ \\
\hline \multirow[t]{2}{*}{ Fever } & Yes, last 2 weeks & 1.00 & $0.71,1.40$ & 1.00 & $0.72,1.37$ & $1 \cdot 21$ & $0.69,2.08$ & 0.84 & $0 \cdot 61,1 \cdot 13$ \\
\hline & No & & & & & & & & \\
\hline \multirow[t]{2}{*}{ Ever vaccination } & Yes & & Ref. & & Ref. & & Ref. & & Ref. \\
\hline & No & $0.71^{*}$ & $0.54,0.94$ & $0.63^{*}$ & $0.49,0.81$ & 0.90 & $0.59,1.41$ & $0.69^{*}$ & $0.56,0.86$ \\
\hline \multirow[t]{2}{*}{ Size of child at birth } & $\begin{array}{l}\text { Larger than average } \\
\text { Average }\end{array}$ & $0.41^{\star}$ & $\begin{array}{l}0.18,0.83 \\
\text { Ref }\end{array}$ & 0.72 & $\begin{array}{l}0.40,1 \cdot 20 \\
\text { Ref. }\end{array}$ & 0.70 & $\begin{array}{l}0.26,1.55 \\
\text { Ref. }\end{array}$ & 0.64 & $\begin{array}{l}0.38,1.01 \\
\text { Ref. }\end{array}$ \\
\hline & Smaller than average & 0.88 & $0.53,1.38$ & 0.83 & $0.52,1.26$ & 0.75 & $0.34,1.47$ & 0.88 & $0.60,1.25$ \\
\hline \multirow[t]{3}{*}{ Total children ever born } & 1 (single child) & & Ref. & & Ref. & & Ref. & & Ref. \\
\hline & 2 or 3 & $1.86^{*}$ & $1 \cdot 34,2 \cdot 61$ & $1.97^{\star}$ & $1.46,2.69$ & 1.57 & $0.98,2.57$ & $1.83^{*}$ & $1.42,2.38$ \\
\hline & 4 or more & $2 \cdot 28^{*}$ & $1.53,3.41$ & $2 \cdot 38^{\star}$ & $1 \cdot 64,3.44$ & 1.37 & $0.70,2.59$ & $2 \cdot 17^{\star}$ & $1.58,2.98$ \\
\hline \multirow[t]{2}{*}{ Delivery by C-section } & Yes & 1.33 & $0.88,1.98$ & $1 \cdot 78^{\star}$ & $1 \cdot 25,2 \cdot 50$ & $1.94^{*}$ & $1 \cdot 12,3 \cdot 31$ & $1 \cdot 84^{*}$ & $1 \cdot 37,2.45$ \\
\hline & No & & Ref. & & Ref. & & Ref. & & Ref. \\
\hline
\end{tabular}

OWOBM/UWC, overweight or obese mother and underweight child; OWOBM/STC, overweight or obese mother and stunted child; OWOBM/WSC, overweight or obese mother and wasted child; OWOBM/USWC, overweight or obese mother and underweight or stunted or wasted child; C-section, caesarean section; ref., reference category.

*Statistical significance at $P<0.05$.

might be the possible cause behind finding a lower proportion of OWOBM/WSC in the current analysis.

Over $6 \%$ of households had a coexistence of an overweight or obese mother and an undernourished child (OWOBM/USWC). It is well established that such coexistence of over- and undernutrition is a consequence of nutrition transition in $\mathrm{LMIC}^{(20)}$. Nutrition transition brings changes in dietary habits and consumption of highenergy-dense foods which, along with less physical activity, result in excessive weight gain among mothers as well as adults in the family ${ }^{(20,21)}$. Foods with high energy density are poor in nutrient content ${ }^{(20)}$. So, the children receive inadequate nutrition which leads to undernutrition ${ }^{(3,20)}$. This can be a possible explanation of MCDB of malnutrition in Bangladesh, as the country has been experiencing a shift in dietary habits over the past few years.

Previous studies showed that MCDB was associated with middle-income households ${ }^{(1,22)}$. Similar to those reports, we also found the middle wealth index category to be associated with OWOBM/STC and OWOBM/UWC. This indicates that poverty is not the cause of MCDB of malnutrition in Bangladesh. Adults from the middle wealth quintile might be more exposed to changes in dietary habits due to nutrition transition in the country, which is evident in many $\mathrm{LMIC}^{(1)}$. Due to increased per capita income, families from the middle wealth quintile are having access to Western foods which is causing 
Table 3 Multivariable analysis using Firth's logistic regression to determine the factors associated with different forms of household-level mother-child double burden of malnutrition in Bangladesh ( $n$ 5951). Data from the Bangladesh Demographic and Health Survey 2014

\begin{tabular}{|c|c|c|c|c|c|c|c|c|c|}
\hline \multirow[b]{2}{*}{ Characteristic } & \multirow[b]{2}{*}{ Response } & \multicolumn{2}{|c|}{ OWOBM/UWC } & \multicolumn{2}{|c|}{ OWOBM/STC } & \multicolumn{2}{|c|}{ OWOBM/WSC } & \multicolumn{2}{|c|}{ OWOBM/USWC } \\
\hline & & OR & $95 \% \mathrm{Cl}$ & OR & $95 \% \mathrm{Cl}$ & OR & $95 \% \mathrm{Cl}$ & OR & $95 \% \mathrm{Cl}$ \\
\hline \multirow[t]{4}{*}{ Mother's education } & No education & & & & & & Ref. & & \\
\hline & Primary & & & & & 1.73 & $0.61,6.24$ & & \\
\hline & Secondary & & & & & 1.14 & $0.38,4.29$ & & \\
\hline & Higher & & & & & 1.33 & $0.33,6.13$ & & \\
\hline \multirow[t]{4}{*}{ Mother's age at first birth } & $\leq 15$ years & & Ref. & & Ref. & & Ref. & & Ref. \\
\hline & $\overline{16}-20$ years & 1.07 & $0.64,1.88$ & $1 \cdot 83^{\star}$ & $1 \cdot 1,3.24$ & 1.17 & $0.56,2.82$ & 1.35 & $0.89,2.09$ \\
\hline & $21-25$ years & $2 \cdot 40^{\star}$ & $1.32,4.52$ & $2 \cdot 45^{\star}$ & $1.32,4.70$ & 1.08 & $0.39,3.08$ & $1.97^{*}$ & $1.18,3.32$ \\
\hline & $\geq 26$ years & 0.83 & $0 \cdot 16,2 \cdot 81$ & 0.29 & $0.01,1.55$ & 0.93 & $0.16,4.06$ & 0.52 & $0.12,1.53$ \\
\hline Mother currently working & $\begin{array}{l}\text { Yes } \\
\text { No }\end{array}$ & & & & & & & & \\
\hline \multirow[t]{4}{*}{ Father's education } & No education & & & & & & Ref. & & Ref. \\
\hline & Primary & & & & & 0.83 & $0.32,2 \cdot 19$ & 1.41 & $0.88,2 \cdot 28$ \\
\hline & Secondary & & & & & 1.92 & $0.80,4.97$ & 2.05 & $1.29,3.33$ \\
\hline & Higher & & & & & 1.86 & $0.59,5.95$ & 1.42 & $0.79,2.57$ \\
\hline \multirow[t]{4}{*}{ Father's occupation } & Farmer & & & & & & & & Ref. \\
\hline & Labour & & & & & & & 0.73 & $0.44,1.19$ \\
\hline & Service/businessman & & & & & & & 1.03 & $0.69,1.54$ \\
\hline & Others (unemployment, retired) & & & & & & & 0.26 & $0.03,0.95$ \\
\hline \multirow[t]{2}{*}{ Place of residence } & Urban & $1 \cdot 28$ & $0.81,2.00$ & 1.20 & $0.8,1.79$ & & & 1.33 & $0.94,1.88$ \\
\hline & Rural & & Ref. & & Ref. & & & & Ref. \\
\hline \multirow[t]{5}{*}{ Wealth index quintile } & Poorest & & Ref. & & Ref. & & Ref. & & Ref. \\
\hline & Poor & $2 \cdot 14$ & $1.00,4.86$ & 1.11 & $0.57,2.16$ & 2.08 & $0.85,5.57$ & 1.39 & $0.80,2.46$ \\
\hline & Middle & $3 \cdot 23^{*}$ & $1.56,7.22$ & $1.96^{*}$ & $1.07,3.70$ & 0.83 & $0 \cdot 26,2 \cdot 61$ & 1.60 & $0.92,2.85$ \\
\hline & Rich & 1.89 & $0.86,4.44$ & 1.56 & $0.82,3.05$ & 0.67 & $0.20,2.20$ & 1.37 & $0.76,2.51$ \\
\hline & Richest & $2 \cdot 01$ & $0.88,4.9$ & 1.21 & $0.59,2.53$ & 1.83 & $0.63,5.76$ & 1.39 & $0.73,2.69$ \\
\hline \multirow[t]{2}{*}{ Family exposed to media } & Television/radio/newspaper & & Ref. & & Ref. & & Ref. & & Ref. \\
\hline & Not at al & $1.90^{*}$ & $1 \cdot 13,3 \cdot 27$ & 1.57 & $0.99,2.53$ & 1.25 & $0.61,2.63$ & $1.47^{*}$ & $1.01,2.22$ \\
\hline \multirow[t]{2}{*}{ Child's age } & $0-23$ months & & Ref. & & Ref. & & Ref. & & Ref. \\
\hline & 24-59 months & 1.22 & $0.80,1.85$ & 0.89 & $0.61,1.29$ & & & 0.99 & $0.72,1.37$ \\
\hline \multirow[t]{2}{*}{ Received deworming drug } & Yes, last 2 weeks & 0.67 & $0.42,1.04$ & 0.80 & $0.53,1.18$ & & & 0.72 & $0.51,1.01$ \\
\hline & No & & Ref. & & Ref. & & & & Ref. \\
\hline \multirow[t]{2}{*}{ Fever } & Yes, last 2 weeks & & & & & & & & \\
\hline & No & & & & Ref. & & & & Ref. \\
\hline \multirow[t]{2}{*}{ Ever vaccination } & Yes & & Ref. & & Ref. & & & & Ref. \\
\hline & No & 0.82 & $0.55,1.24$ & $0.67^{\star}$ & $0.47,0.97$ & & & 0.84 & $0.62,1 \cdot 17$ \\
\hline \multirow[t]{3}{*}{ Size of child at birth } & Larger than average & $0.41^{*}$ & $0.18,0.83$ & & & & & & \\
\hline & Average & & Ref. & & Ref. & & & & \\
\hline & Smaller than average & 0.93 & $0.56,1.47$ & & & & & & \\
\hline \multirow[t]{3}{*}{ Total children ever born } & 1 (single child) & & Ref. & & Ref. & & & & Ref. \\
\hline & 2 or 3 & $2 \cdot 71^{*}$ & $1.70,4.47$ & $2 \cdot 49^{\star}$ & $1.66,3.8$ & & & $2 \cdot 59^{\star}$ & $1.84,3.71$ \\
\hline & 4 or more & $4.03^{*}$ & $2.14,7.54$ & $4.09^{*}$ & $2.35,7.06$ & & & $4 \cdot 72^{*}$ & $2.93,7.60$ \\
\hline Delivery by $\mathrm{C}$-section & Yes & & & $1 \cdot 78$ & $\begin{array}{c}1 \cdot 20,2 \cdot 60 \\
\text { Def }\end{array}$ & 1.37 & $\begin{array}{l}0.73,2.54 \\
\text { Ref }\end{array}$ & $1 \cdot 68^{*}$ & $\begin{array}{c}1 \cdot 20,2 \cdot 33 \\
\end{array}$ \\
\hline
\end{tabular}

OWOBM/UWC, overweight or obese mother and underweight child; OWOBM/STC, overweight or obese mother and stunted child; OWOBM/WSC, overweight or obese mother and wasted child; OWOBM/USWC, overweight or obese mother and underweight or stunted or wasted child; C-section, caesarean section, ref., reference category.

${ }^{*}$ Statistical significance at $P<0.05$.

excess energy intakes ${ }^{(5,22)}$. Excess energy intake contributes to adult overweight and obesity ${ }^{(23)}$, but the phenomenon is complex in children. Childhood undernutrition is interlinked with biological responses to environmental conditions, caring behaviours in the family, diet quality, micronutrient adequacy and morbidity ${ }^{(24)}$. Perhaps families with excess energy intake lack improvement in most of those factors as well as sufficient micronutrient intakes for children, which ultimately leads to DBM. In addition, there might be some social or cultural norms pertaining to food choices and intra-family food distribution that need to be investigated. Several studies revealed that the coexistence of overweight or obese mother and underweight child is more common in urban settings ${ }^{(1,17)}$. We also found the same result for OWOBM/UWC, OWOBM/STC and OWOBM/USWC in bivariate analyses. In urban areas, adult family members have to work outside the home to earn money; hence the family depends on commercially available low-priced foods which are poor in nutrient content. Commercially prepared foods are usually energy-dense and provide energy to adults, but adversely affect the nutritional status of children $^{(17,25)}$. This can be the probable explanation for higher risks of MCDB among those living in urban areas. However, the findings became insignificant after adjusting for the confounders in our multivariable analyses. 
We found maternal age at first child birth and having more than one child to be significantly associated with the risk of MCDB of malnutrition. Females are prone to attaining excess BMI with increase of age and parity ${ }^{(17)}$. Several studies have also suggested that mother's age is positively associated with $\mathrm{MCDB}^{(19)}$. Whether this is related to poor postpartum resolution of the weight gained during pregnancy is not known for Bangladesh. Moreover, a larger number of young children in the same household is known to affect the availability of foods for children ${ }^{(17)}$. This might be indicative of rendering less care and attention towards the younger children of the family.

The present study revealed that households not at all exposed to information media are more at risk of developing MCDB of malnutrition, especially in the forms of OWOBM/UWC and OWOBM/USWC. Television, radio and newspapers can influence behaviour and prevent negative health-related practices ${ }^{(26)}$. Therefore, exposure to mass media campaigns may reduce the risk of MCDB of malnutrition.

Child delivery through C-section was found to be a significant contributor to DBM in Bangladesh. C-section was significantly associated with OWOBM/STC, OWOBM/ WSC and OWOBM/USWC in bivariate analyses. After adjustment, only OWOBM/USWC was significantly associated with C-section delivery of the child. Studies have confirmed that undernutrition and obesity, both forms of malnutrition, are linked with gut microbiota alterations in children $^{(27)}$. It is also reported that C-section delivery contributes to microbial alterations in the small intestine $^{(28,29)}$. Therefore, the association of DBM with delivery through C-section is consistent with the previous study results.

Size of the child at birth larger than average was found to be protective against OWOBM/UWC. Since data regarding size at birth were subjective, there might be chance of recall bias. We observed that history of no vaccination was protective against DBM, especially against OWOBM/UWC. However, we did not find any scientific explanation supporting this finding and recommend future prospective studies to elucidate the association of vaccination with the presence of DBM.

The present study depicts the current scenario of different forms of household-level DBM and its relationship with important sociodemographic correlates. The use of a nationwide representative sample from both urban and rural areas is the strength of the study. However, the study has some limitations. Because the study design was crosssectional, establishment of causality between the identified factors and DBM was not possible. The BDHS 2014 was not designed to address and analyse the presence of household-level DBM. Therefore, we were not able to follow any conceptual framework to comprehensively explain the burden in the context of Bangladesh. We only analysed the sociodemographic determinants of DBM. Determinants such as dietary intake, physical activity, caregiving practices, postpartum weight resolution and cultural influences were not evaluated. So, further exploration is warranted to ascertain the contribution of these potential determinants on development of various forms of MCDB of malnutrition in Bangladesh.

\section{Conclusion}

Nutrition and socio-economic transition are playing crucial roles in pulling the trend of DBM upwards in Bangladesh and other LMIC. The current study indicates the existence of MCDB of malnutrition in Bangladesh with the persistence of potential sociodemographic correlates contributing to the burden. The findings of the current study reinforce that malnutrition prevention programmes must not ignore the nutrition concerns of the whole household to prevent the burgeoning risk of MCDB in Bangladesh. Such programmes also need to be tagged with family planning and increasing awareness through social and behaviour change counselling and exposure to information media.

\section{Acknowledgements}

Acknowledgements: The authors would like to acknowledge the DHS Program and the BDHS 2014, which was made possible by the generous support of the American people through the US Agency for International Development (USAID). They also acknowledge the contribution of icddr,b's core donors (including Government of the People's Republic of Bangladesh; Global Affairs Canada (GAC), Canada; Swedish International Development Cooperation Agency (SIDA); and the Department for International Development, UKAid) for their continuous support and commitment to the icddr,b's research efforts. Financial support: This research received no specific grant from any funding agency in the public, commercial or notfor-profit sectors. Conflict of interest: None of the authors had any conflict of interest to declare. Authorship: S.D. and S.M.F. are joint first authors. S.D. and S.M.F. developed the study concept. S.D., S.M.F. and T.B. contributed to the study design. S.D., M.S.I. and S.M.F. participated in the data analysis and discussion. S.D. and S.M.F. wrote the first draft. S.D., S.M.F., T.B., T.A. and M.M. critically reviewed the drafts. All authors have seen and approved the final draft of the manuscript. Ethics of human subject participation: Informed consent was obtained from the participants of BDHS 2014 after notifying them about the purpose of the survey.

\section{Supplementary material}

To view supplementary material for this article, please visit https://doi.org/10.1017/S1368980018003580 


\section{References}

1. Sekiyama M, Jiang HW, Gunawan B et al. (2015) Double burden of malnutrition in rural West Java: household-level analysis for father-child and mother-child pairs and the association with dietary intake. Nutrients 7, 8376-8391.

2. Ramirez-Zea M, Kroker-Lobos MF, Close-Fernandez R et al. (2014) The double burden of malnutrition in indigenous and nonindigenous Guatemalan populations. Am J Clin Nutr 100, issue 6, 1644S-1651S

3. Kimani-Murage EW, Muthuri SK, Oti SO et al. (2015) Evidence of a double burden of malnutrition in urban poor settings in Nairobi, Kenya. PLoS One 10, e0129943.

4. Kapoor S \& Anand K (2002) Nutritional transition: a public health challenge in developing countries. I Epidemiol Community Health 56, 804-805

5. El Kishawi RR, Soo KL, Abed YA et al. (2016) Prevalence and associated factors for dual form of malnutrition in mother-child pairs at the same household in the Gaza StripPalestine. PLoS One 11, e0151494.

6. Dewey KG \& Begum K (2011) Long-term consequences of stunting in early life. Matern Child Nutr 7, 5-18.

7. Misra A, Singhal N, Sivakumar B et al. (2011) Nutrition transition in India: secular trends in dietary intake and their relationship to diet-related non-communicable diseases. J Diabetes 3, 278-292.

8. Doak CM, Adair LS, Monteiro C et al. (2000) Overweight and underweight coexist within households in Brazil, China and Russia. J Nutr 130, 2965-2971.

9. Hanandita W \& Tampubolon G (2015) The double burden of malnutrition in Indonesia: social determinants and geographical variations. SSM Popul Health 1, 16-25.

10. National Institute of Population Research and Training, Mitra and Associates, \& ICF International (2014) Bangladesh Demographic and Health Survey BDHS 2014: Key Indicators. Dhaka and Calverton, MD: NIPORT, Mitra and Associates, and ICF International.

11. Siddiquee T, Bhowmik B, Moreira NCDV et al. (2015) Prevalence of obesity in a rural Asian Indian (Bangladeshi) population and its determinants. BMC Public Health 15, 860.

12. Oddo VM, Rah JH, Semba RD et al. (2012) Predictors of maternal and child double burden of malnutrition in rural Indonesia and Bangladesh. Am J Clin Nutr 95, 951-958.

13. World Health Organization (2017) The Double Burden of Malnutrition: Policy Brief. Geneva: WHO.

14. NHLBI Obesity Education Initiative Expert Panel on the Identification, Evaluation, and Treatment of Obesity in Adults (1998) Clinical Guidelines on the Identification, Evaluation, and Treatment of Overweight and Obesity in Adults: The Evidence Report. Bethesda, MD: National Heart, Lung, and Blood Institute.
15. Firth D (1993) Bias reduction of maximum likelihood estimates. Biometrika 80, 27-38.

16. Heinze G, Ploner M, Dunkler D et al. (2013) logistf: Firth's bias reduced logistic regression. $\mathrm{R}$ package version 1 . https://rdrr.io/cran/logistf/ (accessed December 2018).

17. Jehn M \& Brewis A (2009) Paradoxical malnutrition in mother-child pairs: untangling the phenomenon of overand under-nutrition in underdeveloped economies. Econ Hum Biol 7, 28-35.

18. Wong C, Zalilah M, Chua E et al. (2015) Double-burden of malnutrition among the indigenous peoples (Orang Asli) of Peninsular Malaysia. BMC Public Health 15, 680.

19. Oddo VM, Rah JH, Semba RD et al. (2012) Predictors of maternal and child double burden of malnutrition in rural Indonesia and Bangladesh. Am J Clin Nutr 95, 951-958.

20. Dieffenbach S \& Stein AD (2012) Stunted child/overweight mother pairs represent a statistical artifact, not a distinct entity. J Nutr 142, 771-773.

21. Kosaka S \& Umezaki M (2017) A systematic review of the prevalence and predictors of the double burden of malnutrition within households. Br J Nutr 117, 1118-1127.

22. Lee J, Houser RF, Must A et al. (2012) Socioeconomic disparities and the familial coexistence of child stunting and maternal overweight in Guatemala. Econ Hum Biol 10, 232-241.

23. Leroy JL, Habicht J-P, González de Cossío T et al. (2014) Maternal education mitigates the negative effects of higher income on the double burden of child stunting and maternal overweight in rural Mexico. J Nutr 144, 765-770.

24. Garrett J \& Ruel MT (2005) The coexistence of child undernutrition and maternal overweight: prevalence, hypotheses, and programme and policy implications. Matern Child Nutr 1, 185-196.

25. Caballero B (2005) A nutrition paradox - underweight and obesity in developing countries. $N$ Engl J Med 352, 1514-1516.

26. Wakefield MA, Loken B \& Hornik RC (2010) Use of mass media campaigns to change health behaviour. Lancet $\mathbf{3 7 6}$, 1261-1271.

27. Pekmez CT, Dragsted LO \& Brahe LK (2018) Gut microbiota alterations and dietary modulation in childhood malnutrition - the role of short chain fatty acids. Clin Nutr. Published online: 17 February 2018. doi: 10.1016/j.clnu.2018.02.014.

28. Dominguez-Bello MG, Costello EK, Contreras $\mathrm{M}$ et al. (2010) Delivery mode shapes the acquisition and structure of the initial microbiota across multiple body habitats in newborns. Proc Natl Acad Sci U S A 107, 11971-11975.

29. Grölund M-M, Lehtonen O-P, Eerola E et al. (1999) Fecal microflora in healthy infants born by different methods of delivery: permanent changes in intestinal flora after cesarean delivery. J Pediatr Gastroenterol Nutr 28, 19-25. 